\title{
High resolution crystal structures of the receptor-binding domain of Clostridium botulinum neurotoxin serotypes $A$ and FA
}

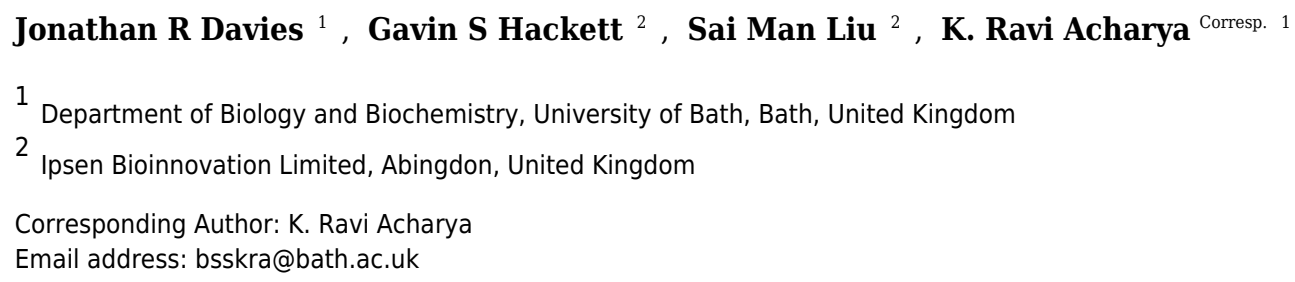

The binding specificity of botulinum neurotoxins (BoNTs) is primarily a consequence of their ability to bind to multiple receptors at the same time. BoNTs consist of three distinct domains, a metalloprotease light chain (LC), a translocation domain $\left(\mathrm{H}_{\mathrm{N}}\right)$ and a receptorbinding domain $\left(\mathrm{H}_{\mathrm{C}}\right)$. Here we report the crystal structure of $\mathrm{H}_{\mathrm{C}} / \mathrm{FA}$, complementing an existing structure through the modelling of a previously unresolved loop which is important for receptor-binding. Our $\mathrm{H}_{\mathrm{C}} / \mathrm{FA}$ structure also contains a previously unidentified disulphide bond, which we have also observed in one of two crystal forms of $H_{C} / A 1$. This may have implications for receptor-binding and future recombinant toxin production. 
1 High resolution crystal structures of the receptor-binding domain of

2 Clostridium botulinum neurotoxin serotypes A and FA

3

4 Jonathan R. Davies ${ }^{1}$, Gavin S. Hackett ${ }^{2}$, Sai Man Liu ${ }^{2}$ and K. Ravi Acharya ${ }^{1}$ 5

6

$7{ }^{1}$ Department of Biology and Biochemistry, University of Bath, Claverton Down, Bath BA2 7AY, 8 UK

9

$10{ }^{2}$ Ipsen Bioinnovation Limited, 102 Park Drive, Milton Park, Abingdon, Oxon OX14 4RY, UK

13 Correspondence

14 K. Ravi Acharya, Department of Biology and Biochemistry, University of Bath, Claverton Down, 15 Bath BA2 7AY, UK; Tel: +44-1225-386238, E-mail: bsskra@,bath.ac.uk 


\section{ABSTRACT}

18 The binding specificity of botulinum neurotoxins (BoNTs) is primarily a consequence of their

19 ability to bind to multiple receptors at the same time. BoNTs consist of three distinct domains, a

20 metalloprotease light chain $(\mathrm{LC})$, a translocation domain $\left(\mathrm{H}_{\mathrm{N}}\right)$ and a receptor-binding domain

$21\left(\mathrm{H}_{\mathrm{C}}\right)$. Here we report the crystal structure of $\mathrm{H}_{\mathrm{C}} / \mathrm{FA}$, complementing an existing structure through

22 the modelling of a previously unresolved loop which is important for receptor-binding. Our

$23 \mathrm{H}_{\mathrm{C}} /$ FA structure also contains a previously unidentified disulphide bond, which we have also

24 observed in one of two crystal forms of $\mathrm{H}_{\mathrm{C}} / \mathrm{A} 1$. This may have implications for receptor-binding

25 and future recombinant toxin production.

\section{Abbreviations}

28 BoNT/X, botulinum neurotoxin serotype X; BoNT/FA, botulinum neurotoxin hybrid of /F and /A

29 serotypes; $\mathrm{H}_{\mathrm{C}}$, receptor binding domain; LC, light chain of BoNT, catalytic domain; $\mathrm{H}_{\mathrm{N}}$,

30 translocation domain of BoNT; SV2C, synaptic vesicle 2 protein, isoform C; TSI, targeted

31 secretion inhibitor. 


\section{INTRODUCTION}

34 Botulinum neurotoxin (BoNT) is the active agent that causes the deadly condition botulism. It is

35 expressed as a single polypeptide chain of approximately $150 \mathrm{kDa}$ and is cleaved post-

36 translationally to yield an active di-chain molecule held together by a single disulphide bond.

37 The smaller $50 \mathrm{kDa}$ light chain (LC) possesses a single zinc-endopeptidase domain whereas the

38 larger $100 \mathrm{kDa}$ heavy chain is comprised of two domains - a target cell receptor binding $\left(\mathrm{H}_{\mathrm{C}}\right)$

39 domain and a translocation $\left(\mathrm{H}_{\mathrm{N}}\right)$ domain (Schiavo et al, 1992; Montecucco, 1986). BoNTs are

40 the most poisonous biological substances known to man and their remarkable toxicity is a result

41 of their highly specific and modular mechanism of action. The toxins target neuronal cell

42 membranes through the formation of a dual receptor binding complex (Montecucco, 1986) which

43 allows for internalisation by endocytosis (Colasante et al, 2013). The $\mathrm{H}_{\mathrm{N}}$ domain then

44 translocates the LC into the cytoplasm where it cleaves a specific SNARE (soluble N-

45 ethylmaleimide-sensitive factor attachment protein receptor) protein which consequently inhibits

46 vesicle release. Many immunologically distinct BoNTs have been discovered over the years -

47 serotypes /A through to /G; although, only serotypes /A, /B, /E and /F have been reported to

48 cause botulism in humans (Coffield et al, 1997). Each serotype can be further subdivided into

49 different subtypes based on their amino acid sequence (Rossetto et al, 2014).

50 The BoNT $\mathrm{H}_{\mathrm{C}}$ domain is responsible for targeting the toxin to a specific cell type and the

51 specific receptors involved have been identified for most serotypes. For example, serotype /A

52 binds to a glycosylated luminal domain of the synaptic vesicle 2 (SV2) protein, preferentially to

53 the C isoform (SV2C) (Dong et al, 2006; Mahrhold et al, 2006), as well as a ganglioside, namely

54 GT1b (Rummel et al, 2004; Yowler \& Schengrund, 2004; Stenmark et al, 2008). X-ray

55 crystallography has revealed protein-backbone hydrogen-bond interactions between $\beta$-strands of 
56

57

the BoNT/A1 $\mathrm{H}_{\mathrm{C}}$ and the fourth luminal domain of SV2C (SV2C-LD4), as well as electrostatic interactions between charged surfaces (Benoit et al, 2014). This is supplemented by additional interactions with the N-linked glycans present on the native SV2 molecule - this network of glycan interactions is key for BoNT potency (Yao et al, 2016).

BoNTs have been exploited for therapeutic use in many neurological indications such as dystonia and overactive bladder (Dressler, 2012). More recently, BoNTs have been reengineered to target different cell types and treat specific clinical indications (Masuyer et al, 2014; Masuyer et al, 2015) - these are known as targeted secretion inhibitors (TSIs). A detailed understanding of the structural aspects of the different BoNT subtypes will prove useful in identifying regions of variability that may help uncover conserved mechanisms of binding, which in turn will guide efforts in developing novel BoNT therapeutics. Therefore, highresolution, three-dimensional structural analysis of naturally occurring BoNTs, their mosaics and subtypes, would be of great value. Of particular interest are the structural differences arising from sequence differences between subtypes.

Recently, a new bivalent strain of Clostridium botulinum, IBCA10-7060, was reported to produce BoNT/B2 and a previously unknown BoNT serotype - "BoNT/H" (Barash \& Arnon, 2014). This novel toxin is a mosaic molecule and is now more commonly referred to as BoNT/FA (as well as BoNT/HA) due to a $\mathrm{LC}$ similar to that of BoNT/F5, a $\mathrm{H}_{\mathrm{N}}$ domain similar to that of BoNT/F1, and a $\mathrm{H}_{\mathrm{C}}$ domain similar to that of BoNT/A1 (Maslanka et al, 2015; GonzalezEscalona et al, 2014; Kalb et al, 2015). The crystal structure of the BoNT/FA binding domain was recently reported (Yao et al, 2017). Here, we present a new crystal structure of $\mathrm{H}_{\mathrm{C}} / \mathrm{FA}$ at $1.95 \AA$ resolution which reveals further structural information that is unresolved in the reported structure. Specifically, our structure reveals a loop previously unmodeled due to lack of density, 
79 which is of high importance, and we also observe a disulphide bond which was not present

80 within the previous structure. To this end we have produced two crystal forms of $\mathrm{H}_{\mathrm{C}} / \mathrm{A} 1$

81 (determined to $1.45 \AA$ and $1.7 \AA$ respectively) differing by the presence of this disulphide bond.

82

83 MATERIALS AND METHODS

84 Cloning and constructs

85 The genes encoding the binding domain of BoNT/A1 $\left(\mathrm{H}_{\mathrm{C}} / \mathrm{A} 1\right)$ and BoNT/FA $\left(\mathrm{H}_{\mathrm{C}} / \mathrm{FA}\right)$ were

86 provided by Ipsen Bioinnovation Ltd. Each was cloned into the pJ401 expression vector (DNA

87 2.0, USA) with an N-terminal 6x histidine tag using standard molecular biology techniques and

88 confirmed by sequencing (Eurofins Genomics, Germany).

89 Protein expression

$90 \mathrm{His}_{6}-\mathrm{H}_{\mathrm{C}} / \mathrm{A} 1$ and $\mathrm{His}_{6}-\mathrm{H}_{\mathrm{C}} / \mathrm{FA}$ were expressed in E. coli strain BL21(DE3) (Novagen, USA) using

91 the following protocol. A glycerol stock was used to inoculate $100 \mathrm{~mL}$ TB medium containing

$9250 \mu \mathrm{g} / \mathrm{mL}$ kanamycin, and grown at $37^{\circ} \mathrm{C}$ for $16 \mathrm{~h}$. From this, $10 \mathrm{~mL}$ of culture was used to

93 inoculate $1 \mathrm{~L}$ TB medium containing $50 \mu \mathrm{g} / \mathrm{mL}$ kanamycin and grown at $37^{\circ} \mathrm{C}$ to an $\mathrm{OD}_{600}$ of

94 0.6. The temperature was reduced to $16^{\circ} \mathrm{C}$ and the cells grown to an $\mathrm{OD}_{600}$ of 1.0 at which point

$950.5 \mathrm{mM}$ isopropyl-d-1-thiogalactopyranoside (IPTG) was added to induce expression. Cells were

96 grown for an additional $16 \mathrm{~h}$ at $16^{\circ} \mathrm{C}$ and then harvested by centrifugation at $4000 \mathrm{x} g$ for $30 \mathrm{~min}$.

\section{Protein purification}

98 Expression cell pastes were resuspended in $0.5 \mathrm{M} \mathrm{NaCl}, 50 \mathrm{mM}$ Tris- $\mathrm{HCl} \mathrm{pH}$ 7.4, $20 \mathrm{mM}$

99 imidazole and lysed using a Constant Systems cell disruptor at $20 \mathrm{kPSI}$. Cell debris were

100 removed by centrifugation at $80000 \mathrm{x} g$ for $30 \mathrm{~min}$ and the supernatant was filtered through a

$1010.22 \mu \mathrm{m}$ membrane syringe filter. The clarified lysate was loaded onto a $5 \mathrm{~mL}$ His Trap column 
102 (GE Healthcare), washed, and the target protein eluted with $0.5 \mathrm{M}$ imidazole. $\mathrm{His}_{6}-\mathrm{H}_{\mathrm{C}} / \mathrm{A} 1$ and

$103 \mathrm{His}_{6}-\mathrm{H}_{\mathrm{C}} / \mathrm{FA}$ were further purified by SEC using a Superdex 200 16/60 column (GE Healthcare)

104 and $0.5 \mathrm{M} \mathrm{NaCl}, 50 \mathrm{mM}$ Tris- $\mathrm{HCl} \mathrm{pH}$ 7.4. Purified samples were concentrated to $10 \mathrm{mg} / \mathrm{mL}$

105 using a $10 \mathrm{kDa}$ MWCO centrifugal filter (Millipore).

106 Crystallography

107 Crystals of $\mathrm{His}_{6}-\mathrm{H}_{\mathrm{C}} / \mathrm{FA}$ and $\mathrm{His}_{6}-\mathrm{H}_{\mathrm{C}} / \mathrm{A} 1$ were grown at $16{ }^{\circ} \mathrm{C}$ using a 1:1 ratio of protein solution

$108(10 \mathrm{mg} / \mathrm{mL})$ to well solution using the sitting-drop vapour-diffusion method $-4 \mathrm{M}$ sodium

109 formate, $0.1 \mathrm{M}$ sodium acetate $\mathrm{pH} 5.5$ for the former, and $0.1 \mathrm{M} \mathrm{MIB} \mathrm{pH} \mathrm{4.0,25 \%} \mathrm{w/v} \mathrm{PEG}$

1101500 for the latter. Crystals were soaked in cryoprotectant (equal volume of reservoir solution

111 and 50\% glycerol) before vitrification in liquid nitrogen. Complete datasets were collected on

112 beamline I03 and I04, respectively, at the Diamond Light Source (Didcot, UK). Diffraction

113 images were processed using DIALS (Gildea et al, 2014) and scaled using AIMLESS (Evans \&

114 Murshudov, 2013) from the CCP4 suite (Winn et al, 2011). Data collection statistics are

115 summarised in Table 1 . A combination of $\mathrm{R}_{\mathrm{pim}}$ and $\mathrm{CC}_{1 / 2}$ value were used to determine the

116 resolution cut-off of $1.95 \AA$ and $1.45 \AA$, respectively. Phase information was determined by

117 molecular replacement using PHASER (McCoy et al, 2007) and a previous structure of $\mathrm{H}_{\mathrm{C}} / \mathrm{A} 1$

118 (PDB: 2VUA; Stenmark et al, 2008) as the initial search model. Multiple rounds of structure

119 refinement were performed by manual correction in COOT (Emsley et al, 2010) followed by

120 restrained refinement with REFMAC5 (Murshudov et al, 2011). Final validation was performed

121 with MolProbity (Chen et al, 2010). Secondary structures were annotated using Stride (Frishman

$122 \&$ Argos, 1995) and figures were prepared using PyMol (Schrödinger, LLC.) and CCP4mg

123 (McNicholas et al, 2011).

124

125 RESULTS AND DISCUSSION 


\section{Crystal structure of BoNT/FA $\mathbf{H}_{\mathrm{C}}$ domain}

127 We identified crystallisation conditions which yielded crystals of $\mathrm{H}_{\mathrm{C}} / \mathrm{FA}$ in space group P422,

128 with two molecules related by non-crystallographic symmetry in the asymmetric unit. This is

129 different to a recently reported structure, PDB: 5V38 (Yao et al, 2017) and reveals an important

130 loop that is involved in receptor binding [average temperature factor (B-factor) $74 \AA^{2}$ ]. A high-

131 multiplicity dataset was collected containing 360 degrees of data over 3600 images. No

132 significant radiation damage was observed over the course of data collection and thus all data

133 were used. The $\mathrm{CC}_{1 / 2}$ value for the outer shell was 0.832 , indicating there was still very usable

134 data at this resolution (Evans \& Murshudov, 2013). The overall structure of $\mathrm{H}_{\mathrm{C}} / \mathrm{FA}$ is shown in

135 Figure 1c and the crystallographic statistics are listed in Table 1. As with all reported structures

136 of the BoNT receptor binding domain, present is a characteristic $\beta$-jellyroll fold at the $\mathrm{N}$-terminal

137 half and a predominantly $\beta$-trefoil fold at the C-terminal half of the protein (Figure 1a-d). Both

138 molecules in the asymmetric unit overlay well with a root mean square deviation (RMSD) value

139 of $0.35 \AA$ between all atoms. The B-factors for each chain are low overall $\left(24.74 \AA^{2}\right.$ and 26.84

$140 \AA^{2}$ respectively) with a corresponding overall Wilson B-factor of $24.55 \AA^{2}$. As expected, our

141 structure is highly similar to PDB: 5V38 with an RMSD value for combinations of chains

142 between structures ranges from $0.54 \AA$ to $0.36 \AA$ (Figure 1d). However, it further reveals the

143 presence of a loop (R1261-R1268) that has been shown in other subtypes to be involved in

144 ganglioside receptor binding (Figure 2a). Crystal packing has enabled neighbouring chains to

145 interact directly with this loop, provide sufficient stabilisation to produce good electron density.

146 Yao et al (2017) suggested that the lack of density was due to high flexibility, which is consistent

147 with the high B-factors we observed in this region relative to the rest of the protein.

148 The specific ganglioside receptor for BoNT/FA is not yet known; however, considering 
149 that GT1b binds with high affinity to BoNT/A1 (Figure $2 b$ ) and that $\mathrm{H}_{\mathrm{C}} / \mathrm{FA}$ and $\mathrm{H}_{\mathrm{C}} / \mathrm{A} 1$ are

150 structurally very similar, we propose that BoNT/FA possesses a similar binding specificity. The

151 overall conformation of this region is also similar to that of BoNT/A1 in complex with a

152 ganglioside receptor (Figure 2). The detailed conformation of this loop is important for

153 understanding receptor binding and our structure confirms that BoNT/FA could bind to

154 gangliosides in a similar manner to BoNT/A. Proximate to the ganglioside binding region, we 155 observe the presence of a disulphide bond between Cys1227 and Cys1272 (Figure 3c) which is

156 also not present in the structure 5V38. The equivalent bond has been observed previously in

157 some, but not all crystal structures of BoNT $\mathrm{H}_{\mathrm{C}}$ Domains; therefore, it is uncertain what role, if 158 any, it may have towards BoNT function.

\section{Crystal structures of the BoNT/A1 binding domain}

160 We have identified a single crystallisation condition that produced two crystal forms of $\mathrm{H}_{\mathrm{C}} / \mathrm{A} 1-$ 161 one possessed the equivalent disulphide bond whereas the other did not. Using $25 \% \mathrm{w} / \mathrm{v}$ PEG

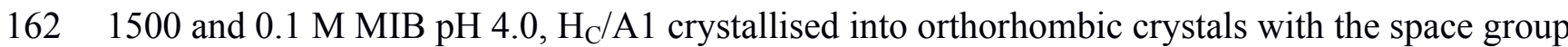

$163 \mathrm{P} 2{ }_{1}{ }_{1} 2_{1}$ (crystal form 1 ) that diffracted to a resolution of $1.45 \AA$. No disulphide bond was

164 observed in this structure (Figure 1a). Instead, Cys1235 rotated away from the junction due to a

165 backbone rotation, bringing the neighbouring Lys1236 toward Cys1280 (Figure 3a). This is

166 consistent with previous $\mathrm{H}_{\mathrm{C}} / \mathrm{A} 1$ structures either in complex with GT1b (PDB: 2VU9; Stenmark

167 et al, 2008), SV2-LD (PDB: 4JRA, 5JLV; Benoit et al, 2014; Yao et al, 2016) or in the apo form

168 (PDB: 2VUA; Stenmark et al, 2008). Using the same conditions, monoclinic crystals were

169 obtained six months later with the space group P2 $2_{1}$ (crystal form 2) that diffracted to $1.8 \AA$

170 resolution. Inspection of this structure (Figure $1 \mathrm{~b}$ ) revealed the presence of a disulphide bond

171 between $\mathrm{C} 1235$ and $\mathrm{C} 1280$, the equivalent of which was also observed in our $\mathrm{H}_{\mathrm{C}} / \mathrm{FA}$ crystal 
172 structure (Figures 3a and 3b) and in a full-length BoNT/A1 crystal structure (PDB: 3BTA; Lacy

$173 \&$ Stevens, 1999). Our findings suggest that the crystallisation condition is not the only

174 determinant as to whether the bond is present or not. The conservation of these cysteine residues

175 across the BoNT sub-serotypes suggests they are very important (Figure 4); however, their

176 precise function is unknown. Almost all BoNT subtypes that cause human botulism contain the

177 two residues. They may be required for disulphide bond formation for structural stability or for

178 efficient function of a nearby ganglioside-binding pocket. It must be noted that the expression

179 system does not appear to select for reduced or non-reduced forms of these cysteine residues -

180 each have been observed in different structures of BoNT/A purified from the native Clostridium

181 botulinum (Garcia-Rodriguez et al. 2007; Stenmark et al, 2008; Fu et al, 2009; Gu et al, 2012;

182 Przedpelski et al, 2013; Benoit et al, 2014; Yao et al, 2017; Davies et al, 2017).

183

\section{CONCLUSION}

185 The high-resolution crystal structures of the binding domains $\left(\mathrm{H}_{\mathrm{C}}\right)$ from BoNT/FA and BoNT/A1

186 are reported here. The former complements a recently published structure (Yao et al, 2017) and

187 resolves a loop which is highly important for receptor binding. For the latter, two structures were

188 determined from two crystal forms obtained from the same crystallisation condition. These

$189 \mathrm{H}_{\mathrm{C}} / \mathrm{A} 1$ structures differed from one another by the presence or absence of a disulphide bond.

190 This bond was also observed in our structure of $\mathrm{H}_{\mathrm{C}} / \mathrm{FA}$. Considering their location near the

191 ganglioside-binding pocket, and conservation across BoNT subtypes, the redox status of these

192 conserved cysteines may have implications in BoNT stability and manufacture. Botulinum

193 neurotoxins are used therapeutically for many indications and their production is currently from

194 the native host Clostridium botulinum. However, considering the safety implications and the 
195 advent of engineered BoNT derivatives, such as TSIs, production from a recombinant source

196 would be highly desirable. The importance of these two cysteine residues is being further

197 investigated.

198

199 ACKNOWLEDGEMENTS

200 The authors would like to thank Diamond Light Source, Didcot (Oxon, UK) for beamtime 201 (proposals mx8922 and mx12342) and the staff of beamlines i03 and i04 for assistance with 202 crystal testing and data collection.

203

204

\section{REFERENCES}

205

206

Barash, JR. \& Arnon, SS. 2014. A novel strain of Clostridium botulinum that produces type B and type H botulinum toxins. J. Infect. Dis. 209: 183-191.

Benoit, RM., Frey, D., Hilbert, M., Kevenaar, JT., Wieser, MM., Stirnimann, CU., McMillan, D., Ceska, T., Lebon, F., Jaussi, R., Steinmetz, MO., Schertler, GF., Hoogenraad, CC., Capitani, G, Kammerer, RA. (2014). Structural basis for recognition of synaptic vesicle protein $2 \mathrm{C}$ by botulinum neurotoxin A. Nature 505, 108-111.

Chen VB, Arendall WB 3rd, Headd JJ, Keedy DA, Immormino RM, Kapral GJ, Murray LW, Richardson JS, Richardson DC. 2010. MolProbity: all-atom structure validation for macromolecular crystallography. Acta Crystallogr. D Biol. Crystallogr. 66: 12-21.

Coffield JA, Bakry N, Zhang RD, Carlson J, Gomella LG, Simpson LL. 1997. In vitro characterization of botulinum toxin types $\mathrm{A}, \mathrm{C}$ and $\mathrm{D}$ action on human tissues: combined electrophysiologic, pharmacologic and molecular biologic approaches. J. Pharmacol. Exp. Ther. 280: 1489-1498. 
218 Colasante C, Rossetto O, Morbiato L, Pirazzini M, Molgo J, Montecucco C. 2013. Botulinum

219 neurotoxin type A is internalized and translocated from small synaptic vesicles at the 220 neuromuscular junction. Mol. Neurobiol. 48: 120-127.

221 Davies JR, Rees J, Liu SM, Acharya KR. 2017. High resolution crystal structures of Clostridium botulinum neurotoxin A3 and A4 binding domains. J Struct Biol. Dec 26. pii: S1047-8477(17)30233-2. doi: 10.1016/j.jsb.2017.12.010. [Epub ahead of print]

Dong M, Yeh F, Tepp WH, Dean C, Johnson EA, Janz R, Chapman ER. 2006. SV2 is the protein receptor for botulinum neurotoxin A. Science 312: 592-596.

Dressler D. 2012. Clinical applications of botulinum toxin. Curr Opin Microbiol. 15: 325-336.

Emsley P, Lohkamp B., Scott, WG, Cowtan K. 2010. Features and development of Coot. Acta Crystallogr. D Biol. Crystallogr. 66: 486-501.

Evans PR \& Murshudov GN. 2013. How good are my data and what is the resolution? Acta Crystallogr. D Biol. Crystallogr. 69: 1204-1214.

Frishman, D \& Argos P. 1995. Knowledge-based protein secondary structure assignment. Proteins 23: 566-579.

Fu Z, Chen C, Barbieri JT, Kim JJ, Baldwin MR. 2009. Glycosylated SV2 and gangliosides as dual receptors for botulinum neurotoxin serotype F. Biochemistry 48: 5631-5641.

Gildea RJ, Waterman DG, Parkhurst JM, Axford D, Sutton G, Stuart DI, Sauter NK, Evans G, 236

Garcia-Rodriguez C, Levy R, Arndt JW, Forsyth CM, Razai A, Lou J, Geren I, Stevens RC, Marks JD. 2007. Molecular evolution of antibody cross-reactivity for two subtypes of type A botulinum neurotoxin. Nat. Biotechnol. 25: 107-116 
241 Gonzalez-Escalona N., Thirunavukkarasu N., Singh A., Toro M., Brown EW, Zink D.,

242 Rummel A, Sharma SK. 2014. Draft genome sequence of bivalent Clostridium botulinum as new therapeutics. Annu. Rev. Pharmacol. Toxicol. 54: 27-51.

Kalb SR, Baudys J, Raphael BH, Dykes JK, Lúquez C, Maslanka SE, Barr JR. 2015. Functional characterization of botulinum neurotoxin serotype $\mathrm{H}$ as a hybrid of known serotypes F and A (BoNT F/A). Anal. Chem. 87: 3911-3917.

Lacy DB. \& Stevens RC. 1999. Sequence homology and structural analysis of the clostridial neurotoxins. J. Mol. Biol. 291: 1091-1104.

Mahrhold, S., Rummel, A., Bigalke, H., Davletov, B. \& Binz, T. 2006. The synaptic vesicle protein $2 \mathrm{C}$ mediates the uptake of botulinum neurotoxin A into phrenic nerves. FEBS Lett. 580: 2011-2014.

Maslanka, SE., Luquez, C, Dykes, JK., Tepp, WH., Pier, CL., Pellett, S., Raphael, B. H., Kalb, SR., Barr, JR., Rao, A. \& Johnson, EA. 2015. A novel botulinum neurotoxin, previously reported as serotype $\mathrm{H}$, has a hybrid-like structure with regions of similarity to the structures of serotypes A and $\mathrm{F}$ and is neutralized with serotype A antitoxin. J. Infect. Dis. 213: $379-385$.

Masuyer G., Chaddock JA, Foster KA, Acharya KR. 2014. Engineered botulinum neurotoxins

Masuyer G, Davies JR, Moore K, Chaddock JA, Acharya KR. 2015. Structural analysis of 
264 Clostridium botulinum neurotoxin type D as a platform for the development of targeted $265 \quad$ secretion inhibitors. Sci. Rep. 5: 13397.

266 McCoy AJ, Grosse-Kunstleve RW, Adams PD, Winn MD, Storoni LC, Read RJ. 2007. Phaser 267 crystallographic software. J. Appl. Cryst. 40: 658-674.

268 McNicholas S, Potterton E, Wilson, KS, Noble MEM. 2011. Presenting your structures: the 269 CCP4mg molecular-graphics software. Acta Crystallogr. D Biol. Crystallogr. 67: 386-394. 270 Montecucco C. 1986. How do tetanus and botulinum toxins bind to neuronal membranes? TiBS $11: 314-317$

272

273

274

275

276

277

278

279

280

281

282

283

284

285

286

Murshudov GN, Skubák P, Lebedev AA, Pannu NS, Steiner RA, Nicholls RA, Winn MD, Long F, Vagin AA. 2011. REFMAC5 for the refinement of macromolecular crystal structures. Acta Crystallogr. D Biol. Crystallogr. 67: 355-367.

Przedpelski A, Tepp WH, Kroken AR, Fu Z, Kim JJ, Johnson EA, Barbieri JT. 2013. Enhancing the protective immune response against botulism. Infect. Immun. 81: 2638-2644.

Rossetto O, Pirazzini M, Montecucco C. 2014. Botulinum neurotoxins: genetic, structural and mechanistic insights. Nat. Rev. Microbiol. 12: 535-549.

Rummel A, Mahrhold S, Bigalke H, Binz T. 2004. The HCC-domain of botulinum neurotoxins A and B exhibits a singular ganglioside binding site displaying serotype specific carbohydrate interaction. Mol Microbiol. 51: 631-643.

Schiavo G, Rossetto O, Santucci A, DasGupta B, Montecucco C. 1992 Botulinum neurotoxins are zinc proteins. J. Biol. Chem. 267: 23479-23483.

Stenmark P, Dupuy J, Imamura A, Kiso M, Stevens RC. 2008. Crystal structure of botulinum neurotoxin type A in complex with the cell surface co-receptor GT1b-insight into the 
toxin-neuron interaction. PLoS Pathog. 4: e1000129.

Terwilliger TC, Grosse-Kunstleve RW, Afonine PV, Moriarty NW, Adams PD, Read RJ, Zwart PH, Hung LW. 2008 Iterative-build OMIT maps: map improvement by iterative model building and refinement without model bias. Acta Crystallogr. D Biol. Crystallogr. 64: $515-524$.

Winn MD, Ballard CC, Cowtan KD, Dodson EJ, Emsley P, Evans PR, Keegan RM, Krissinel EB, Leslie AG, McCoy A, McNicholas SJ, Murshudov GN, Pannu NS, Potterton EA, Powell HR, Read RJ, Vagin A, Wilson KS. 2011. Overview of the CCP4 suite and current developments. Acta Crystallogr. D Biol. Crystallogr. 67: 235-242.

Yao G, Lam KH, Perry K, Weisemann J, Rummel A, Jin R. 2017. Crystal structure of the receptor-binding domain of botulinum neurotoxin type HA, also known as type FA or H. Toxins (Basel) 9: pii: E93.

Yao G, Zhang S, Mahrhold S, Lam KH, Stern D, Bagramyan K, Perry K, Kalkum M, Rummel A, Dong M, Jin, R. 2016. N-linked glycosylation of SV2 is required for binding and uptake of botulinum neurotoxin A. Nat. Struct. Mol. Biol. 23, 656-662.

Yowler BC, Schengrund CL. 2004. Glycosphingolipids-sweets for botulinum neurotoxin. Glycoconj. J 21: 287-293. 


\section{Figure 1}

Crystal structures of HC domains.

(a) HC/A1 domain (crystal form 1, PDB: 5MK6), (b) HC/A1 domain (crystal form 2, PDB: 5MK7),

(c) HC/FA domain (PDB: 5MK8), and (d) overlay with a different crystal form of HC/FA

(PDB:5V38; Yao et al., 2017). The position of loop R1261-R1268 indicated with an ellipse. All

structures represented as a ribbon diagram, generated using PyMol (Schrödinger, LLC.). 

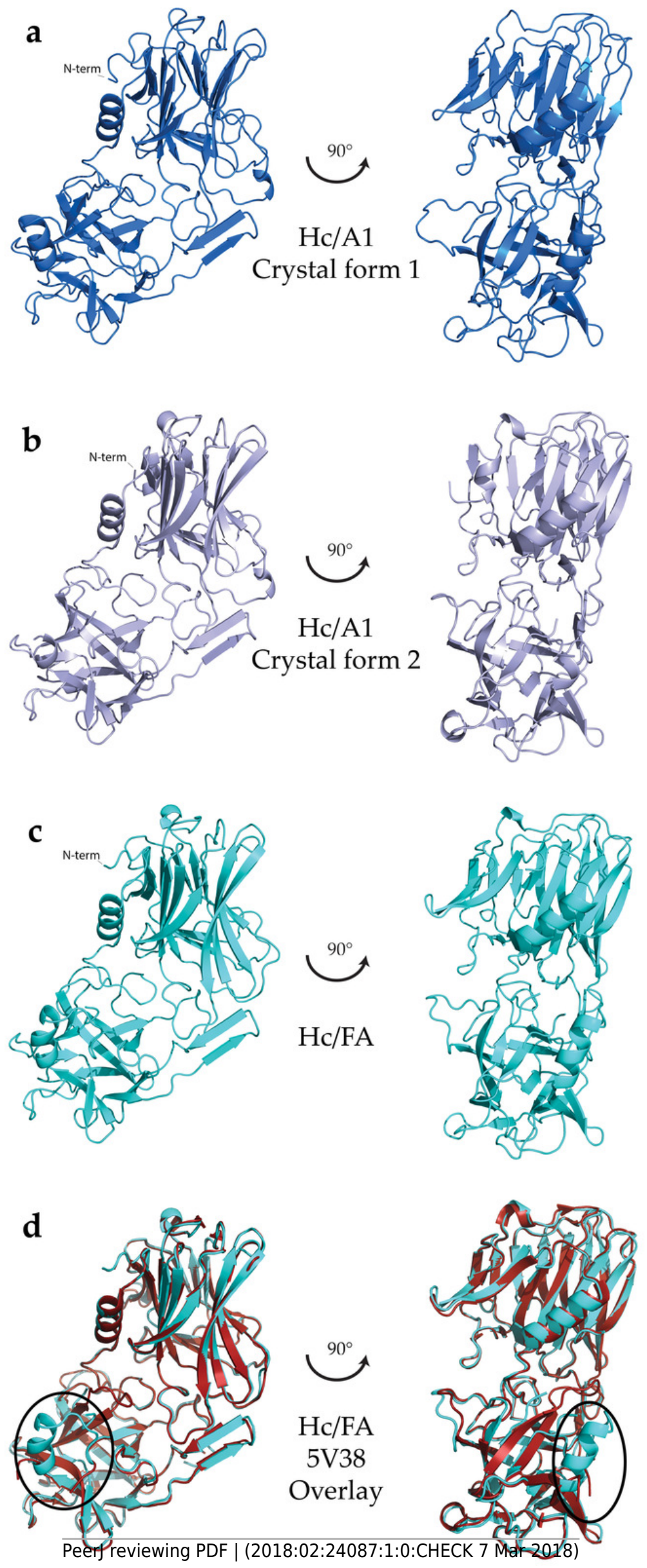
Figure 2

Ganglioside binding site.

(a) Electron density from a composite omit map for HC/FA. The location of a disulphide bond is marked with an asterisk. (b) The equivalent loop from HC/A1 (2VU9) with GT1b shown in glycoblock representation. Map produced using Phenix package (Terwilliger et al, 2008).
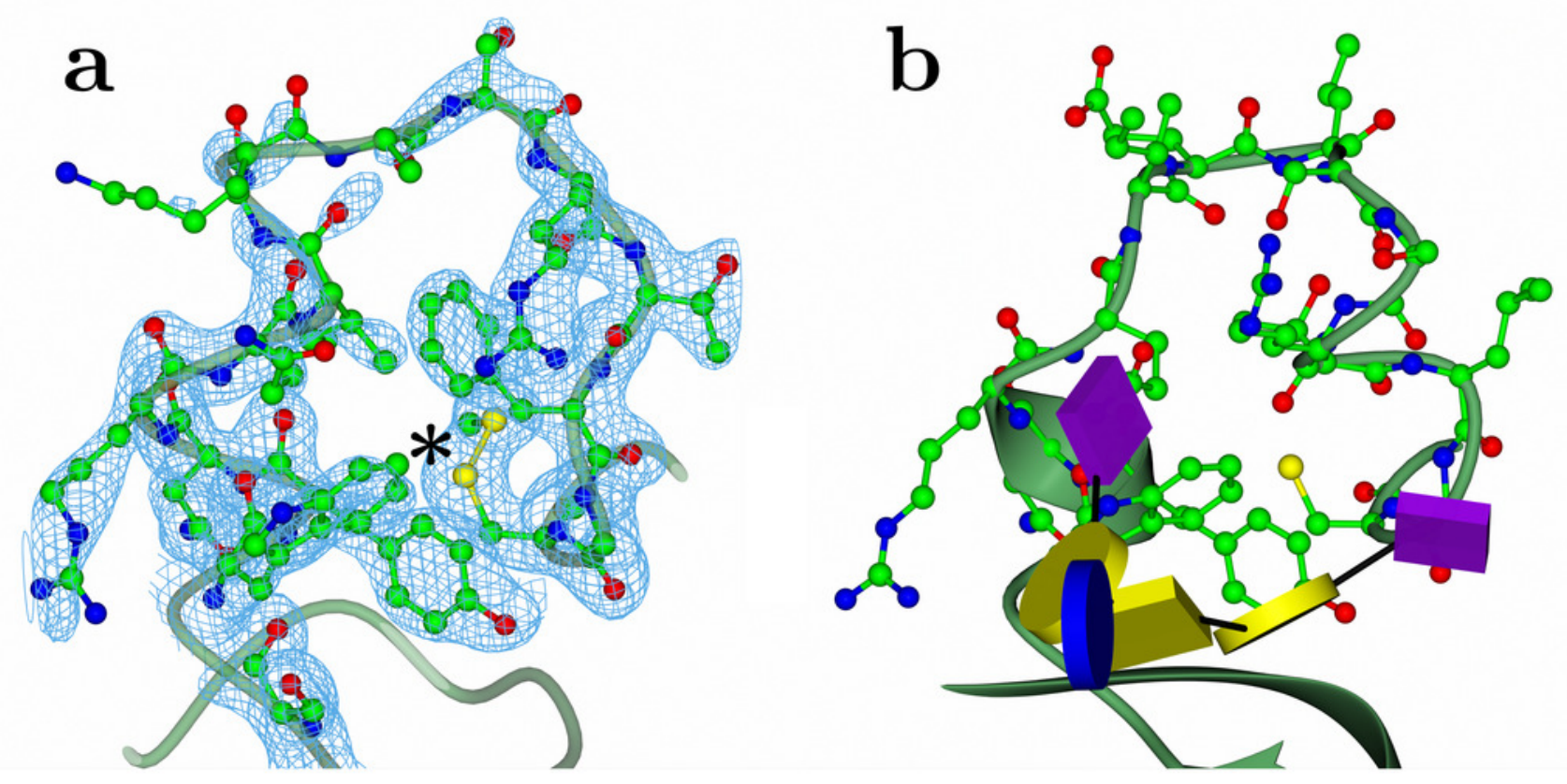


\section{Figure 3}

Location of Cys1235 and Cys1280 residues.

(a) Cys1235 and Cys1280 are not covalently bound in the HC/A1 crystal form 1, (b) disulphide bond formation in crystal form 2 and (c) a similar disulphide bond is seen in the HC/FA crystal structure between equivalent cysteines. Composite OMIT maps were produced using Phenix (Terwilliger et al, 2008). And are shown for each model at $1 \sigma$. Figure generated using CCP4MG (McNicholas et al, 2011). 

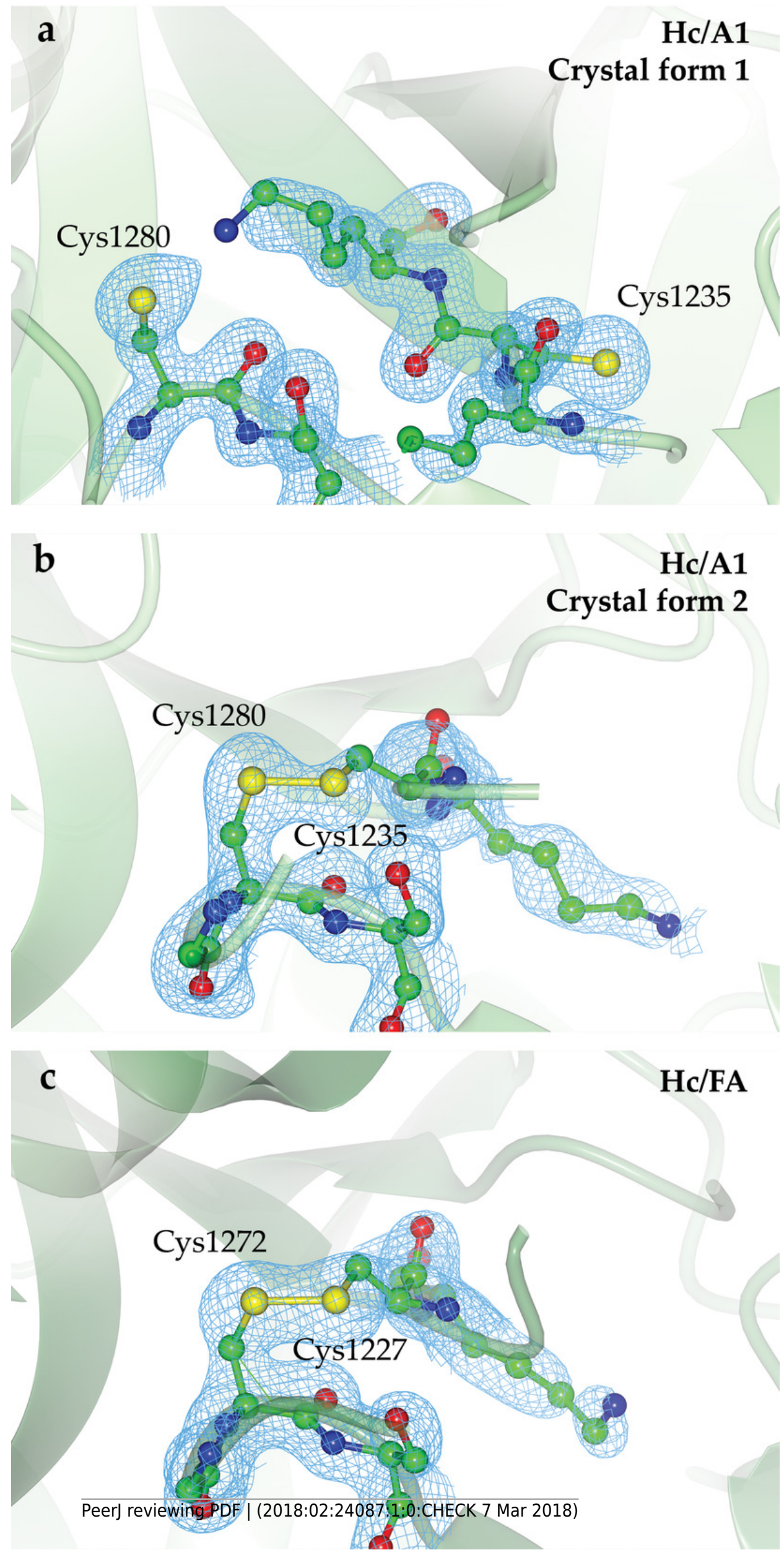
Figure 4

Amino acid sequence alignment of BoNT subtypes emphasising the strong conservation of two cysteine residues near the protein C-terminus.

UniprotKB accession numbers - A1:A5HZZ9, A2:Q45894, A3:Q3LRX9, A4:Q3LRX8, A5:C1IPK2, A6:C9WWY7, A7:K4LN57, A8:A0A0A7PDB7, HA(FA):WP_047402807*, B1:P10844,

B2:A0A0B4W2B0, B3:A2I2S2, B4:A2I2S4, B5:A0A0E1L271, B6:H3K0G8, B7:H9CNK9,

B8:M9VUL2, E1:Q00496, E2:A212S6, E3:A0A076L133, E4:P30995, E5:Q9K395, E6:A8Y878,

E7:G8I2N7, E8:G8I2N8, E9:WP_017352936*, E10:A0A076JVL9, E11:A0A076K0B0,

E12:A0A0A7RCR1, F1:A7GBG3, F2:Q9ZAJ5, F3:D2KHR6, F4:D2KHQ8, F5:D2KHQ9, F6:D2KHS6, F7:D2KHS9, F8:WP_076177537*, F9:A0A1P8YWK9, G:Q60393, X:WP_045538952* (* indicates $\mathrm{NCBI}$ accession code where UniprotKB accession is not available). 
Table $\mathbf{1}$ (on next page)

Crystallographic data collection and refinement statistics. 


\begin{tabular}{|c|c|c|c|}
\hline & $\mathbf{H}_{\mathrm{C}} / \mathbf{F A}$ & $\mathrm{H}_{\mathrm{C}} / \mathrm{A1}$ (crystal form 1) & $\mathrm{H}_{\mathrm{C}} / \mathrm{A} 1$ (crystal form 2$)$ \\
\hline Space Group & P422 & $\mathrm{P} 22_{1} 2_{1} 2_{1}$ & $\mathrm{P} 2_{1}$ \\
\hline \multicolumn{4}{|l|}{ Cell dimensions } \\
\hline$a, b, c(\AA)$ & $118.0,118.0,173.8$ & $39.8,107.3,107.6$ & $61.4,53.9,62.7$ \\
\hline$\alpha, \beta, \gamma\left({ }^{\circ}\right)$ & $90.0,90.0,90.0$ & $90.0,90.0,90.0$ & $90.0,106.1,90.0$ \\
\hline Resolution ( $(\AA)$ & $24.40-1.95(1.98-1.95)^{*}$ & $24.10-1.45(1.48-1.45)^{*}$ & $60.24-1.80(1.84-1.80)^{*}$ \\
\hline $\mathbf{R}_{\text {merge }}(\%)$ & $20.1(168.6)^{*}$ & $7.6(69.2)^{*}$ & $14.2(53.9)^{*}$ \\
\hline$R_{\text {meas }}(\%)$ & $20.8(176.0)^{*}$ & $9.7(92.0)^{*}$ & $15.0(58.8)^{*}$ \\
\hline $\mathbf{R}_{\text {pim }}(\%)$ & $5.6(50.2)^{*}$ & $5.8(60.1)^{*}$ & $4.6(22.5)^{*}$ \\
\hline $\mathrm{CC} 1 / 2$ & $0.999(0.832)^{*}$ & $0.997(0.357)^{*}$ & $0.962(0.954)^{*}$ \\
\hline$<\mathbf{I} /$ sigI $>$ & $12.6(2.3)^{*}$ & $6.9(1.3)^{*}$ & $14.4(3.7)^{*}$ \\
\hline Completeness (\%) & $100.0(100.0)^{*}$ & $95.3(95.1)^{*}$ & $98.6(89.1)^{*}$ \\
\hline Multiplicity & $26.0(23.7)^{*}$ & $3.3(2.7)^{*}$ & $20.4(11.7)^{*}$ \\
\hline$R_{\text {work }}(\%)$ & 18.0 & 17.6 & 18.8 \\
\hline $\mathbf{R}_{\text {free }}(\%)$ & 20.9 & 22.1 & 22.3 \\
\hline \multicolumn{4}{|l|}{ No. of atoms } \\
\hline Protein & 6907 & 3511 & 3263 \\
\hline Water & 609 & 421 & 322 \\
\hline RMSD bond length $(\AA)$ & 0.007 & 0.002 & 0.005 \\
\hline RMSD bond angle ( ${ }^{\circ}$ ) & 0.89 & 0.44 & 0.73 \\
\hline Wilson B factor $\left(\AA^{2}\right)$ & 24.6 & 15.9 & 13.4 \\
\hline \multicolumn{4}{|l|}{ Average $B$ factors $\left(\AA^{2}\right)$} \\
\hline Protein & $28.2,30.0$ & 21.2 & 22.5 \\
\hline Solvent & 33.8 & 34.1 & 28.0 \\
\hline \multicolumn{4}{|l|}{ Ramachandran plot } \\
\hline Favoured (\%) & 96.7 & 96.3 & 96.4 \\
\hline Allowed (\%) & 3.4 & 3.5 & 3.6 \\
\hline Disallowed (\%) & 0.0 & 0.2 & 0.0 \\
\hline PDB code & 5МK8 & 5МK6 & 5MK7 \\
\hline
\end{tabular}

*Values in parentheses are for the highest resolution shell 